\title{
Preoperative color Doppler ultrasonography predicts early recurrence in AFP-positive hepatocellular carcinoma
}

\author{
MIAO CHEN ${ }^{1 *}$, DUO WANG $^{1 *}$, YUAN ZHAO ${ }^{2 *}$, DAN-MEI LU ${ }^{3}$, \\ HONG-XUE LI ${ }^{1}$, JUN-JIE LIU ${ }^{1}$ and HANG LI ${ }^{1}$ \\ Departments of ${ }^{1}$ Ultrasound and ${ }^{2}$ Hepatobiliary Surgery, Affiliated Tumor Hospital of Guangxi Medical University; \\ ${ }^{3}$ Department of Ultrasound, The First People's Hospital of Nanning, Nanning, \\ Guangxi Zhuang Autonomous Region 530021, P.R. China
}

Received May 4, 2018; Accepted April 12, 2019

DOI: $10.3892 / \mathrm{ol} .2019 .10825$

\begin{abstract}
The present study aimed to evaluate the hepatic hemodynamics of patients with $\alpha$-fetoprotein (AFP)-positive hepatocellular carcinoma (HCC) and early recurrence (ER), as determined by color Doppler ultrasound. Screening with color Doppler ultrasound was performed in 150 patients with AFP-positive HCC, yielding 43 cases with postoperative ER. In addition, 35 healthy controls were enrolled in the study for comparison of the blood flow parameters between the healthy control and the HCC groups. Receiver operating characteristic curve analysis was performed to evaluate the predicted effect of Doppler for the ER of HCC. The average mean flow velocity of portal vein in patients with HCC $(14.686 \pm 5.873 \mathrm{~cm} / \mathrm{s})$ was significantly lower in the HCC group compared with the healthy control group $(17.631 \pm 3.569 \mathrm{~cm} / \mathrm{s} ; \mathrm{P}=0.005)$. Additionally, the preoperative portal vein diameter in the HCC group was significantly higher compared with that in the healthy control group $(\mathrm{P}=0.001)$. Regarding the effect of surgery, the portal vein diameter was significantly increased in the patients postoperatively compared with preoperatively $(\mathrm{P}=0.003)$, while the pulsation and resistance indexes exhibited a decreasing trend in the postoperative group $(\mathrm{P}=0.001$ and $\mathrm{P}=0.003$, respectively). Notably, patients with HCC and ER presented with a higher resistance index $(1.163 \pm 0.342)$ compared with
\end{abstract}

Correspondence to: Dr Hang Li or Dr Jun-Jie Liu, Department of Ultrasound, Affiliated Tumor Hospital of Guangxi Medical University, 71 Hedi Road, Nanning, Guangxi Zhuang Autonomous Region 530021, P.R. China

E-mail: lihang58@126.com

E-mail: 85519644@qq.com

${ }^{*}$ Contributed equally

Abbreviations: HCC, hepatocellular carcinoma; AFP, $\alpha$-fetoprotein; $\mathrm{ER}$, early recurrence; LR, late recurrence; ROC, receiver operating characteristic

Key words: color Doppler ultrasound, hepatocellular carcinoma, early recurrence, hepatic hemodynamics the ER-free group $(1.023 \pm 0.176 ; \mathrm{P}=0.004)$. Furthermore, a significant difference in hepatic artery pulsation index was also observed between the ER group $(0.673 \pm 0.075)$ and the ER-free group $(0.624 \pm 0.056 ; \mathrm{P}=0.018)$, indicating that an increased hepatic artery pulsation index may significantly predict the ER of HCC. In addition, areas under the curve of 0.683 and 0.700 , respectively, suggested that the hepatic artery resistance and pulsation indexes may be used to diagnose ER in HCC $(\mathrm{P}=0.009$ and $\mathrm{P}=0.004$, respectively). Taken together, Doppler ultrasound provides a reliable and accurate quantification of hepatic hemodynamics for detecting ER in HCC with a good diagnostic accuracy.

\section{Introduction}

Hepatocellular carcinoma (HCC) is the sixth most common malignant tumor worldwide and one of the most common causes of cancer-associated mortality worldwide $(1,2)$. Ultrasonography, computed tomography examination and serum $\alpha$-fetoprotein (AFP) levels are well-characterized approaches for the diagnosis of early $\operatorname{HCC}(3,4)$; however, prognosis of patients with HCC remains poor (5). Surgical resection is the preferred treatment for HCC (6). However, postoperative recurrence is the main cause of early mortality in patients with HCC following radical resection $(7,8)$. Poon et al (9) reported that the prognosis of patients with HCC and early recurrence (ER; $<1$ year after surgical resection) is worse than that of patients with late recurrence (LR; >1 year), indicating that the shorter the interval time prior to recurrence, the worse the prognosis. Portolani et al (10) reported that the disease-free survival rate within 1 year following surgery is only $68.0 \%$. As a result, the prediction of postoperative ER is particularly important, and therefore it was the main aim of the present study.

Ultrasound is considered the first choice for screening HCC due to its noninvasive, convenient and inexpensive imaging characteristics (11). Ultrasound can evaluate the size, number, position and boundary of tumor nodules, as well as monitoring hepatic hemodynamic changes. Cirrhosis is a serious liver disease, and advanced cirrhosis can easily develop into HCC (12). Doppler ultrasound has been used to detect hemodynamic changes that occur during the 
progression and occurrence of hepatic fibrogenesis associated with cirrhosis (13). Previous research has demonstrated that Doppler ultrasound may be reliably used to assess hemodynamic changes in different stages of liver fibrosis (14). Furthermore, a study conducted by Suk et al (15) demonstrated that changes in hepatic hemodynamics may serve as a predictor for the clinical stages of HCC. Yang et al (16) proposed that the occurrence of HCC is associated with abnormal liver hemodynamics. Combined measurement of AFP levels and Doppler ultrasound has a greater diagnostic accuracy for HCC compared with ultrasonography alone. It has also been recognized that the diagnostic role of AFP together with abdominal ultrasound may effectively predict the risk of HCC development (17). However, to the best of our knowledge, the potential diagnostic value of preoperative Doppler ultrasound for ER of AFP-positive HCC has not been fully investigated thus far.

In the present study, the predicted value of hepatic hemodynamics for the ER of AFP-positive HCC was retrospectively assessed using Doppler ultrasound. Doppler ultrasound parameters were specifically evaluated in AFP-positive HCC and control groups. Furthermore, the present study investigated whether the hepatic artery and portal vein blood flow parameters were associated with postoperative ER of AFP-positive HCC.

\section{Materials and methods}

Clinical data. The present study was performed with approval from the Ethics Committee of the Guangxi Medical University Affiliated Tumor Hospital and written informed consent was obtained from all participants. All the 150 patients with HCC received surgical treatment and were diagnosed by pathologists for the first time in the Guangxi Medical University Affiliated Tumor Hospital between September 2015 and December 2016. In total, the 137 AFP-positive patients with HCC (threshold, $400 \mathrm{ng} / \mathrm{ml}$ ) were followed-up for 1 year following surgical treatment. The patients included 115 males and 22 females with a mean age of $47.82 \pm 11.43$ years (range, 20-71 years). A total of 13 patients with AFP-positive HCC were lost to follow-up. Subsequently, the patients were divided into different groups according to their ER status, an ER group and an ER free group. The 35 healthy controls were enrolled from the outpatients department of the Guangxi Medical University Affiliated Tumor Hospital between September 2015 and December 2016 and consented to an ultrasound examination of their liver. The healthy controls included 20 males and 15 females, with a mean age of $53.26 \pm 8.75$ years (range, 35-67 years).

Ultrasound examination. A standard ultrasonographic study was performed utilizing standard equipment (GE Logiq9 color Doppler; GE Healthcare Life Sciences) and a transducer ultrasound probe ( 2.5 or $3.5 \mathrm{MHz}$ with low acoustic power). The enrolled subjects did not use drugs that affect hemodynamics (including nonselective $\beta$-blockers and vasopressin analogues) 5 days prior to the examination, Subjects were fasted for 6-8 $\mathrm{h}$ and allowed to rest for $30 \mathrm{~min}$ prior to the examination. Two-dimensional ultrasound images were used to evaluate the size, location, boundary, internal echo and blood flow of the liver-occupying lesions. The blood flow parameters of the hepatic artery and portal vein were measured by color Doppler ultrasound. All of the subjects were laid flat and the ultrasonic probe was placed intercostally. The hepatic blood flow of the portal and hepatic arteries was detected between the neck of the gallbladder and the inferior vena cava. The following Doppler ultrasound parameters were measured: i) Portal vein blood flow of the mean flow velocity; ii) portal venous blood flow volume; iii) portal vein diameter; iv) hepatic artery pulsation index (PI); and v) hepatic artery resistance index (RI). To ensure reliability, all parameters were measured $\geq 3$ times simultaneously and the mean value was calculated. When patients with HCC were followed up for 3 months following the operation, results were similar to the pre-operative exam. The tests were performed by two experienced ultrasound physicians, and conflicting opinions were discussed and resolved by a third physician.

Statistical analysis. All statistical analyses were performed using SPSS software (version 22.0; IBM Corp.). The results are presented as the mean \pm standard deviation. An independent Student's t-test was used for comparisons between two groups. A paired Student's t-test was utilized to compare hepatic hemodynamics changes in the preoperative and postoperative stages in the same patient. The Chi-squared test was used to analyze the qualitative data including sex, tumor number, tumor thrombi, liver cirrhosis and hepatitis. Receiver operating characteristic (ROC) curves were generated to evaluate the diagnostic accuracy of Doppler ultrasonography for ER in patients with HCC. $\mathrm{P}<0.05$ was considered to indicate a statistically significant difference.

\section{Results}

Baseline characteristics. A total of 150 patients (including 128 males and 22 females) with AFP-positive HCC and 35 healthy controls were recruited at the Affiliated Tumor Hospital of Guangxi Medical University (Nanning, China) between September 2015 and December 2016 (Table I). In total, 13 patients were loss to follow-up and 137 patients with AFP-positive HCC (mean age, $48.360 \pm 11.482$ years) completed the follow-up. Among these patients, 41 cases were diagnosed with postoperative ER (ER group) and 96 cases were free of postoperative ER (ER-free group). The patients were classified into a liver cirrhosis group $(n=61)$ and a non-liver cirrhosis group $(n=76)$, according to their cirrhosis status. In the healthy control group, 20 males and 15 females were included. The characteristics of the patients are summarized in Table II.

Change in hepatic hemodynamics between preoperative patients with HCC and healthy controls. The change in hepatic hemodynamics between patients with HCC and the control group was evaluated (Fig. 1). The mean flow velocity $(14.686 \pm 5.873 \mathrm{~cm} / \mathrm{sec})$ in patients with HCC was significantly lower compared with that observed in healthy subjects $(17.631 \pm 3.569 \mathrm{~cm} / \mathrm{sec} ; \mathrm{P}=0.005$; Fig. 2A). Additionally, the results revealed that patients with $\mathrm{HCC}$ presented with significantly higher portal vein diameters $(1.085 \pm 0.149 \mathrm{~cm})$ compared with the healthy control group $(0.991 \pm 0.155 \mathrm{~cm}$; $\mathrm{P}=0.001$; Fig. 2B). There was no statistical significance difference in the other parameters, including portal venous 
Table I. Baseline pre-operative clinical characteristics of the enrolled patients.

\begin{tabular}{|c|c|}
\hline Variables & $\mathrm{n}$ \\
\hline \multicolumn{2}{|l|}{ Sex } \\
\hline Male & 128 \\
\hline Female & 22 \\
\hline \multicolumn{2}{|l|}{ Age, years } \\
\hline Mean \pm SD & $48.36 \pm 11.48$ \\
\hline \multicolumn{2}{|c|}{ Tumor number } \\
\hline Multiple & 47 \\
\hline Single & 102 \\
\hline \multicolumn{2}{|c|}{ Tumor thrombi } \\
\hline Yes & 86 \\
\hline No & 64 \\
\hline \multicolumn{2}{|c|}{ Tumor diameter $(\mathrm{cm})$} \\
\hline Mean \pm SD & $7.58 \pm 3.92$ \\
\hline \multicolumn{2}{|c|}{ Liver cirrhosis } \\
\hline Yes & 68 \\
\hline No & 82 \\
\hline \multicolumn{2}{|l|}{ Hepatitis } \\
\hline Yes & 143 \\
\hline No & 7 \\
\hline \multicolumn{2}{|c|}{ Early recurrence } \\
\hline Yes & 41 \\
\hline No & 96 \\
\hline
\end{tabular}

SD, standard deviation.

flow velocity, portal venous volume, hepatic artery RI and PI, between the preoperative HCC group and the healthy control group (Table III).

Effect of surgery on the hemodynamics of patients with HCC. The hemodynamic changes prior to and following the surgical procedure in patients with HCC were compared using paired Student's t-test. The portal vein diameter significantly increased upon operation (pre-operative, $1.07 \pm 0.14 \mathrm{~cm}$ vs. post-operative, $1.14 \pm 0.19 \mathrm{~cm} ; \mathrm{P}=0.003$; Fig. $3 \mathrm{~A}$ ). The effect of surgery on the hepatic artery was evaluated. The results revealed that the PI presented the same trend in the post-operative group (pre-operative group, $1.095 \pm 36.331 \mathrm{~cm}$; post-operative group, $1.330 \pm 0.260 \mathrm{~cm} ; \mathrm{P}=0.001$; Fig. 3B). Additionally, the RI in the post-operative group $(0.690 \pm 0.060)$ was significantly higher compared with that observed in the pre-operative group (0.650 $\pm 0.080 ; \mathrm{P}=0.003$; Table IV; Fig. 3C).

Comparison of hemodynamic changes between patients with $H C C$ and postoperative ER and ER-free patients with HCC. The hemodynamic changes between the ER group (Fig. 4) and the ER-free group (Fig. 5) were compared. Notably, the postoperative ER group exhibited a significantly increased hepatic artery PI (0.673 \pm 0.075 vs. $0.624 \pm 0.056 ; \mathrm{P}=0.018$; Fig. $6 \mathrm{~A}$; Table V) compared with the ER-free group. Furthermore, a
Table II. Clinical characteristics of ER and ER-free patients.

\begin{tabular}{llll}
\hline & & ER-free & \\
Variables & ER group, $n$ & group, $n$ & P-value
\end{tabular}

\section{Sex}

Male

37

78

0.216

Female

4

18

Age, years

Mean \pm SD

$46.34 \pm 11.410 \quad 48.45 \pm 11.439$

0.325

Tumor number

Multiple

$15 \quad 28$

0.419

Single

25

68

Tumor thrombi

Yes

$28 \quad 51$

$13 \quad 45$

Tumor diameter $(\mathrm{cm})$

Mean \pm SD

$9.25 \pm 3.621$

$6.82 \pm 3.628$

$<0.05^{\mathrm{a}}$

Liver cirrhosis

Yes

22

39

0.190

No

19

57

Hepatitis

Yes

41

90

0.178

No

0

6

${ }^{a} \mathrm{P}<0.05$ was considered to indicate a statistically significant difference. $\mathrm{ER}$, early recurrence; $\mathrm{SD}$, standard deviation.

statistically significant difference in RI was observed between the ER and ER-free groups, indicating that the RI in the ER group (1.163 \pm 0.342$)$ was significantly lower than that of the ER-free group $(1.023 \pm 0.176 ; \mathrm{P}=0.004$; Fig. 6B, Table V). For the other parameters measured, including average flow velocity, portal venous blood flow volume and portal vein diameter, no statistically significant differences were observed between the ER group and the ER-free group (Table V).

Diagnostic accuracy of Doppler ultrasonography for the diagnosis of ER in HCC. ROC curve analysis was performed to assess the diagnostic accuracy of Doppler ultrasonography for the diagnosis of ER in patients with HCC. The area under the ROC curve (AUC) of preoperative RI value was 0.683 (range, 0.564-0.801; $\mathrm{P}=0.009$ ). An AUC value for RI of 0.645 corresponded with the highest diagnostic value for ER with a sensitivity of $68 \%$ and a specificity of $70.91 \%$ (Fig. 7A). As for the preoperative PI, an AUC of 0.700 suggested a high diagnostic accuracy of preoperative PI for the ER of patients with HCC (range, 0.583-0.818; $\mathrm{P}=0.004$ ). The best cut-off value of pre-operative PI was 1.045 , with a sensitivity of $72.00 \%$ and a specificity of $67.27 \%$ (Table VI; Fig 7B).

\section{Discussion}

Surgical resection is the first choice for the treatment of HCC. However, recurrence subsequent to resection is one of the main factors affecting the prognosis of HCC (18). 
Table III. Blood flow parameters of the portal vein and hepatic artery in health controls and patients with HCC.

\begin{tabular}{|c|c|c|c|c|c|c|c|}
\hline \multirow[b]{2}{*}{ Variable } & \multicolumn{3}{|c|}{ Healthy control group } & \multicolumn{3}{|c|}{ HCC group } & \multirow[b]{2}{*}{ P-value } \\
\hline & $\mathrm{n}$ & Mean & SD & $\mathrm{n}$ & Mean & SD & \\
\hline \multicolumn{8}{|c|}{ Hepatic artery } \\
\hline RI & 35 & 0.663 & 0.048 & 86 & 0.654 & 0.077 & 0.524 \\
\hline PI & 35 & 1.185 & 0.217 & 86 & 1.1116 & 0.306 & 0.442 \\
\hline \multicolumn{8}{|l|}{ Portal vein } \\
\hline $\mathrm{V}, \mathrm{cm} / \mathrm{s}$ & 35 & 17.631 & 3.569 & 146 & 14.686 & 5.873 & $0.005^{\mathrm{a}}$ \\
\hline $\mathrm{Q}, \mathrm{ml} / \mathrm{min}$ & 35 & 466.349 & 165.623 & 150 & 535.635 & 229.640 & 0.094 \\
\hline $\mathrm{D}, \mathrm{cm}$ & 35 & 0.991 & 0.155 & 150 & 1.085 & 0.149 & $0.001^{\mathrm{a}}$ \\
\hline
\end{tabular}

${ }^{a} \mathrm{P}<0.05$ was considered to indicate a statistically significant difference. HCC, hepatocellular carcinoma; SD, standard deviation; RI, resistance index; PI, pulsation index; V, average flow velocity; Q, portal venous blood flow volume; D, portal vein diameter.
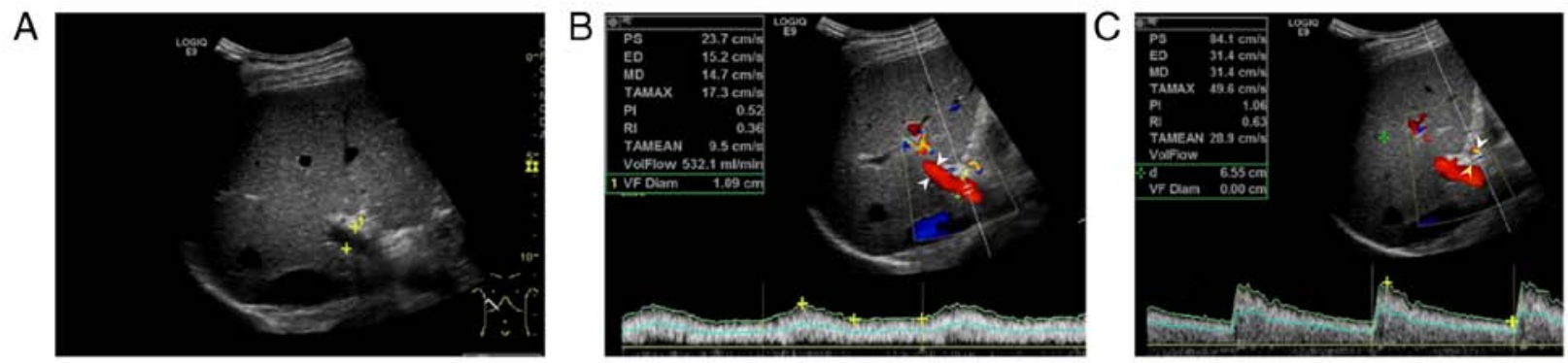

Figure 1. Results from a 50-year-old healthy control. (A) Two-dimensional ultrasound image. (B) Color Doppler blood flow diagram of the portal vein (D, $1.09 \mathrm{~cm} ; \mathrm{V}, 14.7 \mathrm{~cm} / \mathrm{sec}$; Q, $532.1 \mathrm{ml} / \mathrm{min}$ ). (C) Color Doppler blood flow diagram of the hepatic artery (white arrowheads; PI, 1.06; RI, 0.63). PS, peak systolic velocity; ED, end-diastolic velocity; VF Diam, portal vein diameter; MD, average flow velocity; VolFlow, portal venous blood flow volume; TAMEAN, time averaged velocity; TAMAX, mean time maximum velocity.

A

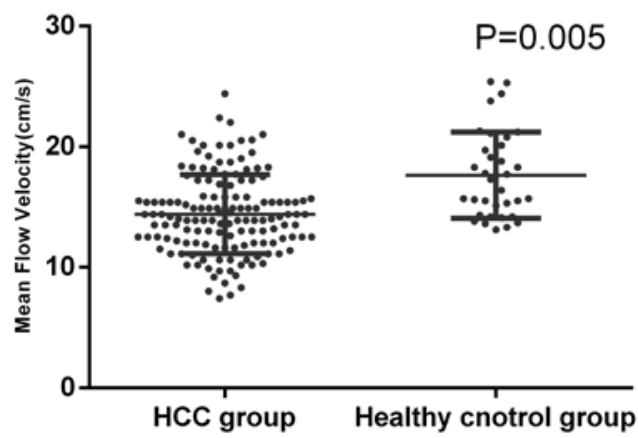

B

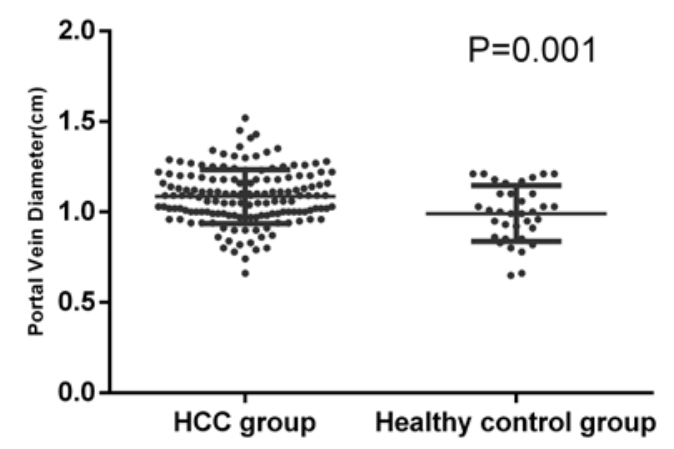

Figure 2. Comparison of the hepatic hemodynamics between the hepatocellular carcinoma group and the healthy control group. (A) Mean flow velocity. (B) Portal vein diameter.

It has become evident that post-operative recurrence of HCC can be classified into ER and LR $(8,9)$. In particular, ER presents challenges for the treatment of liver cancer. Colecchia et al (19) demonstrated that ER may originate from the liver metastasis of primary tumors, which is mainly associated with biological factors of the tumor, including tumor size, number of lesions and vascular invasion. LR is caused by the residual liver state, and is affected by the history of
HCC prior to treatment and the presence of hepatitis and cirrhosis (20). A reliable and effective prediction method to assess the risk of HCC recurrence may shed light on future treatment strategies.

The examination of blood vessels morphology and hemodynamics may directly or indirectly reflect the inherent biological characteristics of tumors (21). As a noninvasive imaging modality, ultrasonography is widely used in routine clinical 
Table IV. Changes of the blood flow parameters of the portal vein pre- and post-surgery in patients with hepatocellular carcinoma.

\begin{tabular}{|c|c|c|c|c|c|c|c|}
\hline \multirow[b]{2}{*}{ Variable } & \multicolumn{3}{|c|}{ Pre-operative } & \multicolumn{3}{|c|}{ Post-operative } & \multirow[b]{2}{*}{ P-value } \\
\hline & $\mathrm{n}$ & Mean & $\mathrm{SD}$ & $\mathrm{n}$ & Mean & SD & \\
\hline \multicolumn{8}{|l|}{ Portal vein } \\
\hline $\mathrm{V}, \mathrm{cm} / \mathrm{s}$ & 107 & 14.680 & 6.540 & 107 & 13.988 & 3.748862749 & 0.287 \\
\hline $\mathrm{Q}, \mathrm{ml} / \mathrm{min}$ & 107 & 526.190 & 245.810 & 107 & 531.600 & 230.780 & 0.868 \\
\hline $\mathrm{D}, \mathrm{cm}$ & 107 & 1.070 & 0.140 & 107 & 1.140 & 0.190 & $0.003^{\mathrm{a}}$ \\
\hline \multicolumn{8}{|c|}{ Hepatic artery } \\
\hline PI & 36 & 1.100 & 0.330 & 36 & 1.330 & 0.260 & $0.001^{\mathrm{a}}$ \\
\hline RI & 36 & 0.650 & 0.080 & 36 & 0.690 & 0.060 & $0.003^{\mathrm{a}}$ \\
\hline
\end{tabular}

${ }^{a} \mathrm{P}<0.05$ was considered to indicate a statistically significant difference. SD, standard deviation; RI, resistance index; PI, pulsation index; $\mathrm{V}$, average flow velocity; $\mathrm{Q}$, portal venous blood flow volume; $\mathrm{D}$, portal vein diameter.
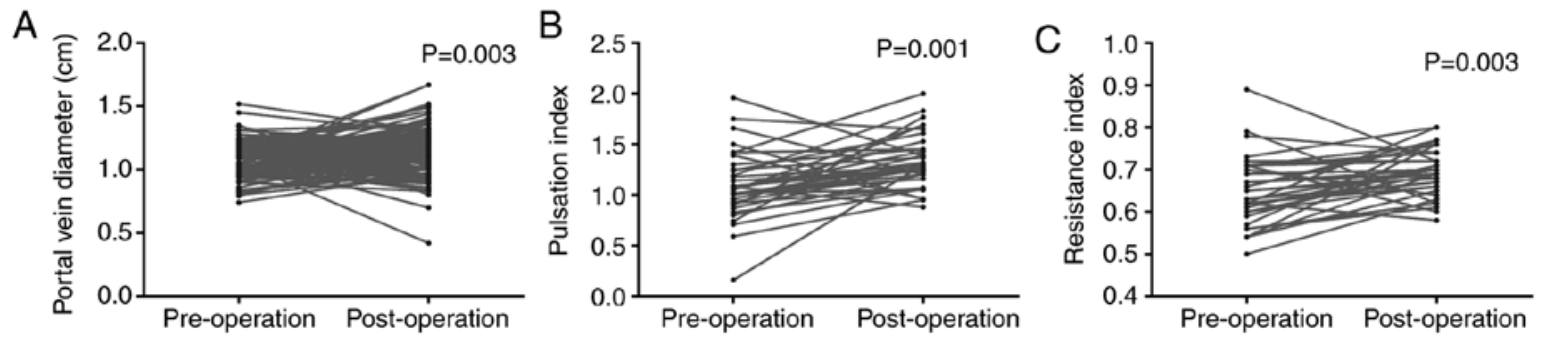

Figure 3. Changes in the hepatic hemodynamics in patients with hepatocellular carcinoma pre- and post-operatively. (A) Portal vein diameter. (B) Pulsation index. (C) Resistance index.
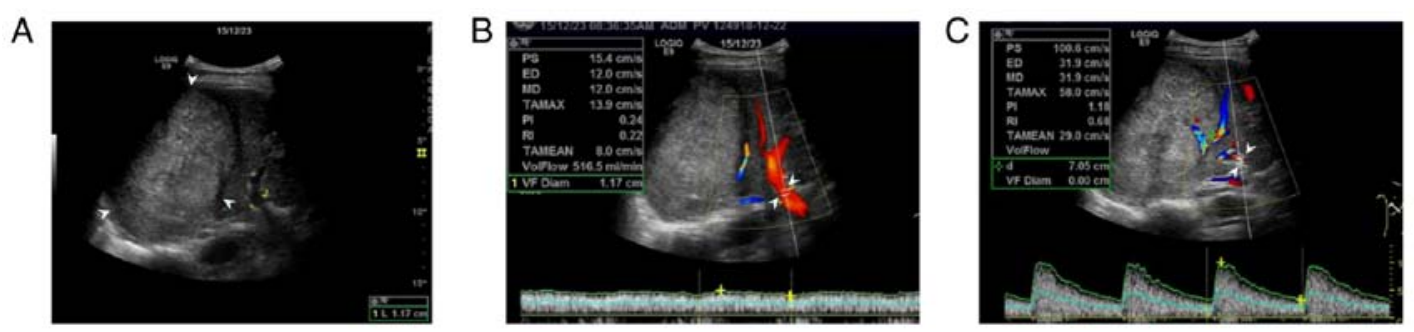

Figure 4. Results from a 45-year-old patient with hepatocellular carcinoma, positive $\alpha$-fetoprotein, liver cirrhosis, Child-Pugh A, tumor pathological stage of intermediate differentiation, Barcelona clinic liver cancer stage B and postoperative early recurrence. (A) Conventional ultrasound image revealing a $14 \mathrm{~cm}$-diameter lesion tumor (white arrowhead). (B) Color Doppler blood flow diagram of the portal vein (white arrowheads; D, $1.17 \mathrm{~cm} ; \mathrm{V}, 12.0 \mathrm{~cm} / \mathrm{sec}$; Q, $516.5 \mathrm{ml} / \mathrm{min}$ ). (C) Color Doppler blood flow diagram of the hepatic artery (white arrowheads; PI, 1.18; RI, 0.68). PS, peak systolic velocity; ED, end-diastolic velocity; MD, average flow velocity; VolFlow, portal venous blood flow volume; VF Diam, portal vein diameter; PI, pulsation index; RI, resistance index; TAMEAN, time averaged velocity; TAMAX, mean time maximum velocity.
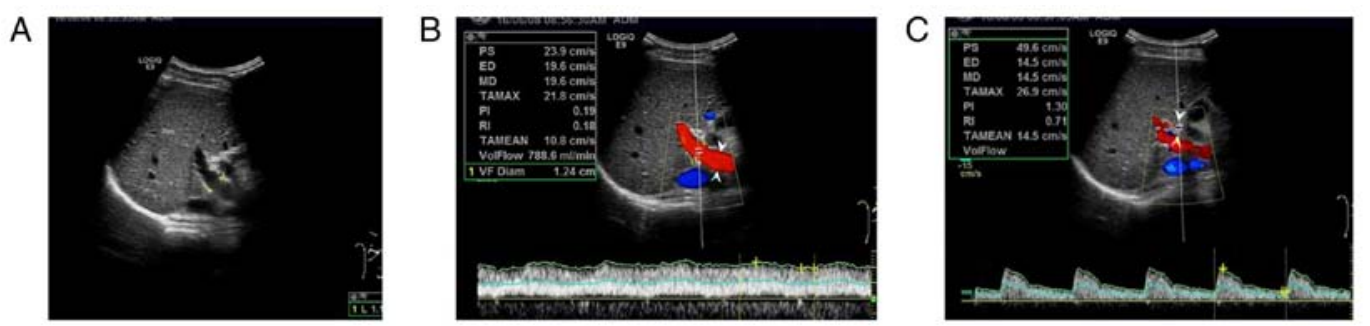

Figure 5. Results from a 65-year-old patient with hepatocellular carcinoma, positive $\alpha$-fetoprotein, no liver cirrhosis, Child-Pugh A, tumor pathological stage of intermediate differentiation, tumor emboli, Barcelona clinic liver cancer stage $\mathrm{C}$ and no early recurrence following surgery. (A) Conventional ultrasound image revealing no early recurrence following surgery. (B) Color Doppler blood flow diagram of the portal vein (white arrowheads; D, $1.24 \mathrm{~cm}$; V, $19.6 \mathrm{~cm} / \mathrm{sec}$; Q, $788.6 \mathrm{ml} / \mathrm{min}$ ). (C) Color Doppler blood flow diagram of the hepatic artery (white arrowheads; PI, 1.30; RI, 0.71). PS, peak Systolic velocity; $\mathrm{ED}$, end-diastolic velocity; MD, average flow velocity; Vloflow, portal venous blood flow volume; VF Diam, portal vein diameter; PI, pulsation index; RI, resistance index, TAMEAN, time averaged velocity; TAMAX, mean time maximum velocity. 
Table V. Blood flow parameters of the portal vein and hepatic artery in the ER-free group and ER group of patients with hepatocellular carcinoma.

\begin{tabular}{|c|c|c|c|c|c|c|c|}
\hline \multirow[b]{2}{*}{ Variables } & \multicolumn{3}{|c|}{ ER-free group } & \multicolumn{3}{|c|}{ ER group } & \multirow[b]{2}{*}{ P-value } \\
\hline & $\mathrm{n}$ & Mean & SD & $\mathrm{n}$ & Mean & SD & \\
\hline \multicolumn{8}{|c|}{ Hepatic artery } \\
\hline RI & 25 & 1.023 & 0.176 & 55 & 1.163 & 0.342 & $0.004^{\mathrm{a}}$ \\
\hline PI & 25 & 0.624 & 0.056 & 55 & 0.673 & 0.075 & $0.018^{\mathrm{a}}$ \\
\hline \multicolumn{8}{|l|}{ Portal vein } \\
\hline $\mathrm{V}, \mathrm{cm} / \mathrm{s}$ & 96 & 14.725 & 6.827 & 37 & 14.284 & 3.261 & 0.687 \\
\hline $\mathrm{Q}, \mathrm{ml} / \mathrm{min}$ & 96 & 520.685 & 244.144 & 41 & 538.344 & 210.213 & 0.708 \\
\hline $\mathrm{D}, \mathrm{cm}$ & 96 & 1.067 & 0.15 & 41 & 1.1 & 0.14 & 0.233 \\
\hline
\end{tabular}

${ }^{a} \mathrm{P}<0.05$ was considered to indicate a statistically significant difference. ER, early recurrence; $\mathrm{SD}$, standard deviation; RI, resistance index; PI, pulsation index; V, average flow velocity; Q, portal venous blood flow volume; D, portal vein diameter.

Table VI. Receiver operating characteristic curve analysis of PI and RI for the diagnosis of ER in patients with hepatocellular carcinoma.

\begin{tabular}{lccccc}
\hline Variables & Area under the curve (range) & P-value & Cut-off & Sensitivity, \% & Specificity, \% \\
\hline RI & $0.683(0.564-0.801)$ & 0.009 & $<0.6450$ & 68.00 & 70.91 \\
PI & $0.700(0.583-0.818)$ & 0.004 & $<1.0450$ & 72.00 & 67.27 \\
\hline
\end{tabular}

RI, resistance index; PI, pulsation index; ER, early recurrence.
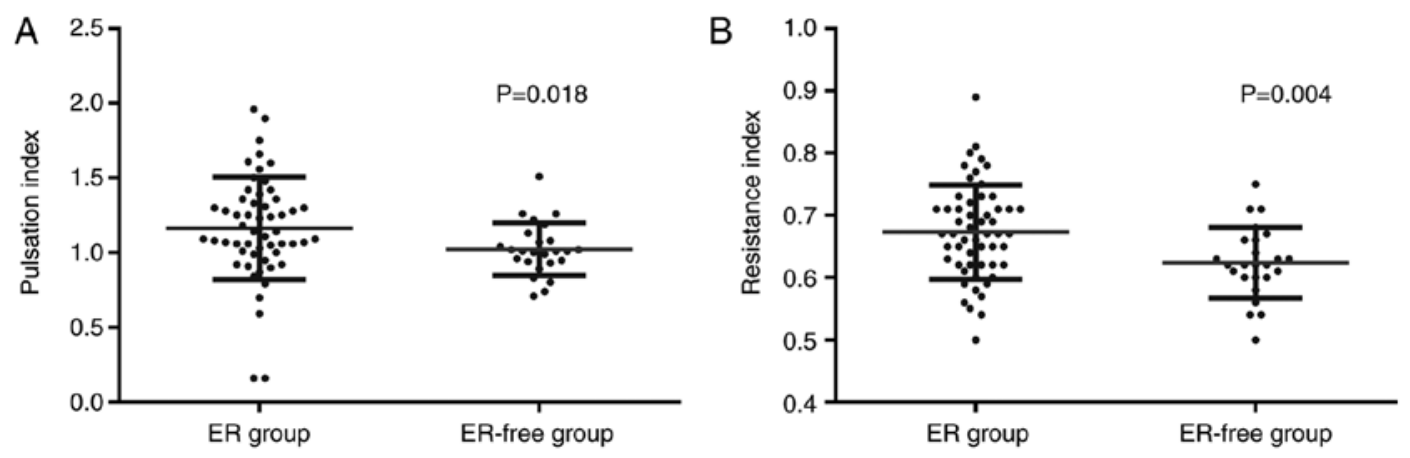

Figure 6. Differences in hepatic hemodynamics between the ER group and the ER-free group. (A) Pulsation index. (B) Resistance index. ER, early recurrence.
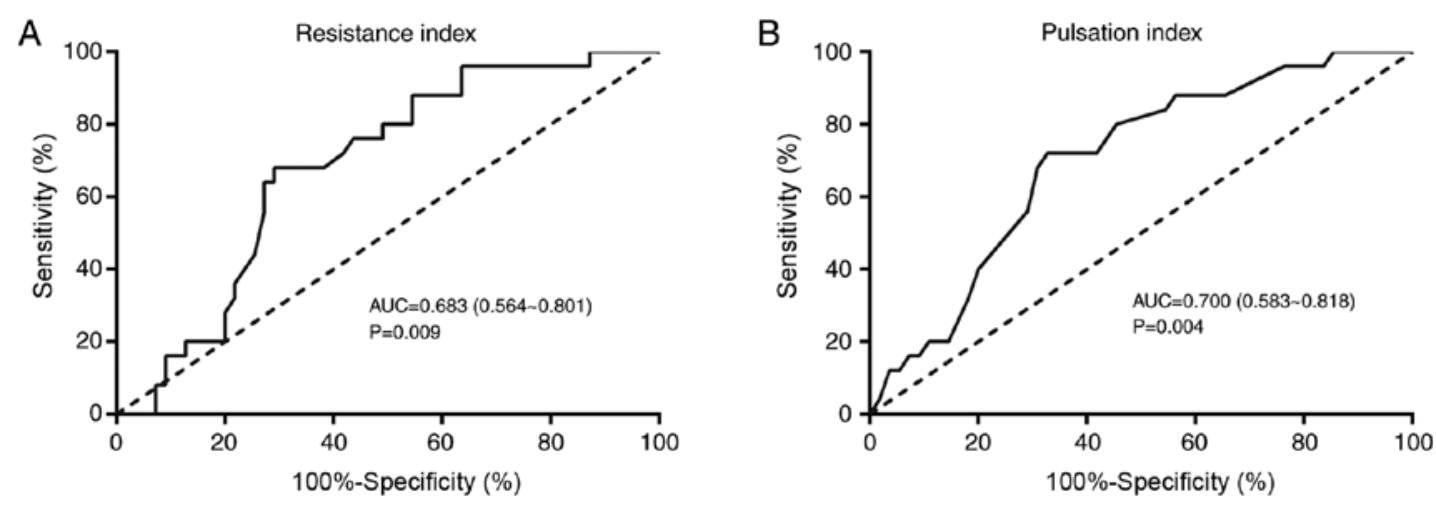

Figure 7. Predicted value of hepatic artery parameters for the early recurrence of hepatocellular carcinoma in patients. (A) Resistance index and (B) pulsation index. AUC, area under the curve. 
practice for diagnosis, treatment planning or monitoring of cancer, particularly for detecting changes in hemodynamics of the portal vein and hepatic artery (22-25). Therefore, it was speculated that the hemodynamics of ultrasound detection may be a valuable predictor for the ER of HCC following resection. It has been demonstrated that the combination of ultrasonography and measurement of AFP levels confers the efficient surveillance strategy for early HCC detection (26). Previous studies have demonstrated that the factors affecting the recurrence of HCC include incomplete or absent tumor capsule, preoperative AFP levels $>400 \mathrm{ng} / \mathrm{l}$, lesion size and positive pathological margin $(25,27-30)$. Clinically, the size and capsule of HCC tumors may be assessed by various imaging methods prior to surgery, while the AFP levels can be detected through laboratory examination. However, pathological grading of tumors and microvascular invasion cannot be obtained prior to pathological examination. Therefore, the prediction of ER of HCC requires future investigation to improve patient prognosis (3). The present study focused on patients with AFP-positive HCC to investigate the diagnostic value of ultrasonography for the recurrence of HCC (31).

Comparison of the hemodynamics between patients with HCC and healthy controls revealed that the pre-operative portal venous blood flow volume and portal vein diameter in patients with HCC were significantly increased compared with the control group, while the preoperative hepatic artery PI in patients with HCC was significantly decreased compared with the control group. The present study demonstrated that monitoring of the hepatic hemodynamics is important for the early diagnosis of HCC recurrence. To the best of our knowledge, no studies on this topic have been conducted thus far. The results obtained in the present study revealed that pre-operative hepatic artery RI and PI in the ER group were significantly lower compared with in the ER-free group. In addition, the ROC curve revealed that pre-operative PI $<1.05$ and RI $<0.645$ may be used as reference values for predicting the occurrence of ER in postoperative HCC. Bonnin et al (32) revealed that the hepatic artery Doppler perfusion index was established earlier during the diagnosis of liver cancer when compared with conventional ultrasonography (37.6 \pm 12.7 days), and that increased blood flow in the hepatic artery may be used to monitor the growth of liver tumors in mice, leading to a diagnosis of liver cancer 4-20 weeks earlier.

Blood to the liver is supplied by the hepatic artery and portal vein. Advanced liver cirrhosis is associated with portal hypertension and portal vein widening, with the majority of cases progressing into HCC. The histopathology of HCC revealed the presence of neovasculature and blood pooling in the tumor. Compared with the same diameter hepatic artery, the lower number of elastic fibers in patients with HCC contributes to a lower hepatic artery blood flow resistance and faster flow rate. In conclusion, the pathological changes of HCC are accompanied by changes in the hemodynamics of the hepatic artery and portal vein (33). Therefore, the early dynamic changes of the hepatic artery and portal vein may be used to predict recurrence in HCC. The application of color Doppler ultrasound for hepatic artery and portal venous hemodynamics is particularly useful for the early diagnosis of $\mathrm{HCC}$ recurrence.
HCC tumor blood is mainly supplied by the hepatic artery, while the portal vein is involved in the peripheral part of the liver and extends to the center with a small branch (34). When the tumor size is $>5 \mathrm{~cm}$, the hepatic artery and portal vein are intertwined to form a vascular lake around the tumor, whereas the tumor blood supply is partially or completely derived from the portal vein when the tumor size is $<5 \mathrm{~cm}(35-37)$. The portal venous system has multiple collateral circulations and may exhibit a small blood flow in HCC with ER $(37,38)$. Therefore, the hepatic artery affects $\mathrm{HCC}$ tumor recurrence more than the portal vein, resulting in no significant changes when the latter is monitored by current ultrasound instrumentation. Hepatic artery PI and RI are the main parameters to reflect the blood flow of the hepatic artery. The hepatic artery hemodynamic changes in liver cancer were previously evaluated by RI and PI in the literature. The PI and RI measurements of the hepatic artery are highly reproducible, easily measured and not affected by the changes in respiration or body position (39). In addition, the ultrasonic detection of PI and RI can be fully quantified. Therefore, the PI and RI of the hepatic artery may be predictors of ER following surgery in HCC.

The present study had several limitations. Firstly, The PI value is affected by heart rate, hemangiectasis ability and the total resistance of peripheral blood vessels (40). Secondly, the limits of the instrument and the operator may lead to discrepancy in the observations. Finally, the retrospective nature and small sample size of the present study may lead to statistical type-II errors. Overall, the sensitivity and specificity of ultrasonic monitoring require improvement. In conclusion, the present study indicated that color Doppler ultrasound detection of hepatic hemodynamics may have significant value for the diagnosis of ER in HCC. It may significantly improve the accuracy of predicting the occurrence of preoperative ER, which may assist clinicians in selecting optimal treatment strategies for patients with HCC.

\section{Acknowledgements}

Not applicable.

\section{Funding}

The present study was supported by the Young Scientists Fund of the National Natural Science Foundation of China (grant no. 81701721), the Guangxi Key Project of Science and Technology (grant no. 2017AB48027) and the Guangxi Natural Science Foundation (grant no. 2016XNSFRA380194).

\section{Availability of data and materials}

All data generated or analyzed during the present study are included in this published article.

\section{Authors' contributions}

HL designed the study and revised the manuscript. JL participated in designing and conducting the research. MC conceived the research and contributed to manuscript writing. DW and DL collected and analyzed the data. YZ and HL analyzed the data and interpreted the results. 


\section{Ethics approval and consent to participate}

The present study was performed with approval of the Ethics Committee of the Guangxi Medical University Affiliated Tumor Hospital and written informed consent was obtained from all participants.

\section{Patient consent for publication}

Not applicable.

\section{Competing interests}

The authors declare that they have no competing interests.

\section{References}

1. Siegel RL, Miller KD and Jemal A: Cancer statistics, 2018. CA Cancer J Clin 68: 7-30, 2018.

2. Tang A, Hallouch O, Chernyak V, Kamaya A and Sirlin CB Epidemiology of hepatocellular carcinoma: Target population for surveillance and diagnosis. Abdom Radiol (NY) 43: 13-25, 2018

3. Ayuso C, Rimola J, Vilana R, Burrel M, Darnell A García-Criado Á, Bianchi L, Belmonte E, Caparroz C, Barrufet $\mathrm{M}$, et al: Diagnosis and staging of hepatocellular carcinoma (HCC): Current guidelines. Eur J Radiol 101: 72-81, 2018.

4. Colombo F, Baldan F, Mazzucchelli S, Martin-Padura I, Marighetti P, Cattaneo A, Foglieni B, Spreafico M, Guerneri S Baccarin M, et al: Evidence of distinct tumour-propagating cell populations with different properties in primary human hepatocellular carcinoma. PLoS One 6: e21369, 2011.

5. Jemal A, Ward EM, Johnson CJ, Cronin KA, Ma J, Ryerson B, Mariotto A, Lake AJ, Wilson R, Sherman RL, et al: Annual report to the nation on the status of cancer, 1975-2014, featuring survival. J Natl Cancer Inst 109: 2017.

6. He W, Peng B, Tang Y, Yang J, Zheng Y, Qiu J, Zou R, Shen J, Li B and Yuan Y: Nomogram to predict survival of patients with recurrence of hepatocellular carcinoma after surgery. Clin Gastroenterol Hepatol 16: 756-764.e10, 2018.

7. Shu T, Zhao D, Li B, Wang Y, Liu S, Li P, Zuo J, Bai P, Zhang R and $\mathrm{Wu}$ L: Prognostic evaluation of postoperative adjuvant therapy for operable cervical cancer: 10 years' experience of National Cancer Center in China. Chin J Cancer Res 29: 510-520, 2017.

8. Wang Y, Liao J, Qi W, Xie L and Li Y: Predictive value of conventional ultrasound and contrast-enhanced ultrasound in early recurrence of hepatocellular carcinoma after surgical resection. Ultrasound Med Biol 42: 1042-1048, 2016.

9. Poon RT, Fan ST, Ng IO, Lo CM, Liu CL and Wong J: Different risk factors and prognosis for early and late intrahepatic recurrence after resection of hepatocellular carcinoma. Cancer 89 500-507, 2000.

10. Portolani N, Coniglio A, Ghidoni S, Giovanelli M, Benetti A, Tiberio GA and Giulini SM: Early and late recurrence after liver resection for hepatocellular carcinoma: Prognostic and therapeutic implications. Ann Surg 243: 229-235, 2006.

11. Gao Y, Zheng DY, Cui Z, Ma Y, Liu YZ and Zhang W: Predictive value of quantitative contrast-enhanced ultrasound in hepatocellular carcinoma recurrence after ablation. World J Gastroenterol 21: 10418-10418, 2015.

12. Kamin PD, Bernardino ME and Green B: Ultrasound manifestations of hepatocellular Carcinoma. Radiology 131: 459-461, 1979.

13. Freitas TP, Gomes M, Fraga DB, Freitas LS, Rezin GT, Santos PM, Silveira PC, Paula MM, Pinho RA and Streck EL: Effect of therapeutic pulsed ultrasound on lipoperoxidation and fibrogenesis in an animal model of wound healing. J Surg Res 161: 168-171, 2010.

14. Zekanovic D, Ljubicic N, Boban M, Nikolic M, Delic-Brkljacic D, Gacina P, Klarin I and Turcinov J: Doppler ultrasound of hepatic and system hemodynamics in patients with alcoholic liver cirrhosis. Dig Dis Sci 55: 458-466, 2010.

15. Suk KT, Kim EJ, Kim DJ, Kim HS, Bang CS, Park TY, Baik GH, Kim SE, Park JW, Park SH, et al: Prognostic significance of hemodynamic and clinical stages in the prediction of hepatocellular carcinoma. J Clin Gastroenterol 51: 285-293, 2017.
16. Yang YL, Di L, Duan YY, Liu X, Liu J, Yang RJ, Chen S and Yuan LJ: A prospective experimental study of liver fibrosis with ultrasound and its correlation with hepatic reserve function and hemodynamics. BMC Gastroenterol 12: 168, 2012.

17. Yang JD, Dai J, Singal AG, Gopal P, Addissie BD, Nguyen MH, Befeler AS, Reddy KR, Schwartz M, Harnois DM, et al: Improved performance of serum alpha-fetoprotein for hepatocellular carcinoma diagnosis in HCV cirrhosis with normal alanine transaminase. Cancer Epidemiol Biomarkers Prev 26: 1085-1092, 2017.

18. Sangiovanni A and Colombo M: Treatment of hepatocellular carcinoma: Beyond international guidelines. Liver Int 36 (Suppl 1): S124-S129, 2016.

19. Colecchia A, Schiumerini R, Cucchetti A, Cescon M, Taddia M, Marasco G and Festi D: Prognostic factors for hepatocellular carcinoma recurrence. World J Gastroenterol 20: 5935-5950, 2014.

20. Tong MJ, Rosinski AA, Huynh CT, Raman SS and Lu DSK: Long-term survival after surveillance and treatment in patients with chronic viral hepatitis and hepatocellular carcinoma. Hepatol Commun 1: 595-608, 2017.

21. Annet L, Materne R, Danse E, Jamart J, Horsmans Y and Van Beers BE: Hepatic flow parameters measured with MR imaging and Doppler US: Correlations with degree of cirrhosis and portal hypertension. Radiology 229: 409-414, 2003.

22. Kondo T, Maruyama H, Sekimoto T, Shimada T, Takahashi M, Okugawa $\mathrm{H}$ and Yokosuka O: Impact of portal hemodynamics on Doppler ultrasonography for predicting decompensation and long-term outcomes in patients with cirrhosis. Scand J Gastroenterol 51: 236-244, 2016.

23. Mäkikallio K, Erkinaro T, Niemi N, Kavasmaa T, Acharya G, Päkkilä $M$ and Räsänen J: Fetal oxygenation and Doppler ultrasonography of cardiovascular hemodynamics in a chronic near-term sheep model. Am J Obstet Gynecol 194: 542-550, 2006.

24. Maruyama $\mathrm{H}$ and Yokosuka $\mathrm{O}$ : Ultrasonography for noninvasive assessment of portal hypertension. Gut Liver 11: 464-473, 2017.

25. Berzigotti A, Reverter E, García-Criado Á, Abraldes JG, Cerini F, García-Pagán JC and Bosch J: Reliability of the estimation of total hepatic blood flow by Doppler ultrasound in patients with cirrhotic portal hypertension. J Hepatol 59: 717-722, 2013.

26. Biselli M, Conti F, Gramenzi A, Frigerio M, Cucchetti A, Fatti G, D'Angelo M, Dall'Agata M, Giannini EG, Farinati F, et al: A new approach to the use of alpha-fetoprotein as surveillance test for hepatocellular carcinoma in patients with cirrhosis. Br J Cancer 112: 69-76, 2015.

27. Lee SY, Konstantinidis IT, Eaton AA, Gönen M, Kingham TP, D'Angelica MI, Allen PJ, Fong Y, DeMatteo RP and Jarnagin WR: Predicting recurrence patterns after resection of hepatocellular cancer. HPB (Oxford) 16: 943-953, 2014.

28. Yang P, Qiu J, Li J, Wu D, Wan X, Lau WY, Yuan Y and Shen F: Nomograms for pre-and postoperative prediction of long-term survival for patients who underwent hepatectomy for multiple hepatocellular carcinomas. Ann Surg 263: 778-786, 2016.

29. Ogihara H, Iizuka N and Hamamoto Y: Prediction of early recurrence of liver cancer by a novel discrete bayes decision rule for personalized medicine. Biomed Res Int 2016: 8567479, 2016.

30. Zhang W, Lai SL, Chen J, Xie D, Wu FX, Jin GQ and Su DK: Validated preoperative computed tomography risk estimation for postoperative hepatocellular carcinoma recurrence. World J Gastroenterol 23: 6467-6473, 2017.

31. Mehta A and Singal AG: Hepatocellular Carcinoma surveillance: Does alpha-fetoprotein have a role. Gastroenterology 149: 816-817, 2015.

32. Bonnin P, Villemain A, Vincent F, Debbabi H, Silvestre JS, Contreres JO, Levy BI, Tobelem G and Dupuy E: Ultrasonic assessment of hepatic blood flow as a marker of mouse hepatocarcinoma. Ultrasound Med Biol 33: 561-570, 2007.

33. Rappaport AM: Hepatic blood flow: Morphologic aspects and physiologic regulation. Int Rev Physiol 21: 1-63, 1980.

34. Kamiyama $\mathrm{T}$, Kakisaka $\mathrm{T}$, Orimo $\mathrm{T}$ and Wakayama $\mathrm{K}$ : Hepatectomy for hepatocellular carcinoma with portal vein tumor thrombus. World J Hepatol 9: 1296-1304, 2017.

35. Dong YH and Lin G: Experimental studies of portal venous embolization with iodized oil in rats with experimentally induced liver cancer. J Vasc Int Radiol 4: 621-624, 1993.

36. Han K, Kim JH, Ko GY, Gwon DI and Sung KB: Treatment of hepatocellular carcinoma with portal venous tumor thrombosis: A comprehensive review. World J Gastroenterol 22: 407-416, 2016. 
37. Giorgio A, Calisti G, Montesarchio L, Scognamiglio U, Matteucci P, Coppola C, Scarano F, Amendola F and Giorgio V: Hepatocellular carcinoma invading portal venous system in cirrhosis: Long-term results of percutaneous radiofrequency ablation of both the nodule and portal vein tumor thrombus. A case control study. Anticancer Res 34: 6785-6790, 2014.

38. Shimada S,KamiyamaT, YokooH,Orimo T, WakayamaK,EinamaT, Kakisaka T, Kamachi $\mathrm{H}$ and Taketomi A: Clinicopathological characteristics of hepatocellular carcinoma with microscopic portal venous invasion and the role of anatomical liver resection in these cases. World J Surg 41: 2087-2094, 2017.
39. Tanaka S, Kitamura T, Fujita M, Nakanishi K and Okuda S: Color Doppler flow imaging of liver tumors. AJR Am J Roentgenol 154: 509-514, 1990.

40. Kamalov IR, Sandrikov VA, Gautier SV, Tsirulnikova OM and Skipenko OG: The significance of colour velocity and spectral Doppler ultrasound in the differentiation of liver tumours. Eur J Ultrasound 7: 101-108, 1998.

(i) () $\ominus$ This work is licensed under a Creative Commons cc) International (CC BY-NC-ND 4.0) License. 